\title{
Association of CK-19 with histopathological grading of oral squamous cell carcinomas (OSCC).
}

1. BDS, MDS

Assistant professor Department of Oral Pathologylsra Dental College, Isra University Hyderabad, Sindh.

2. BDS, MSc

Assistant Professor

Department of Oral Pathology,

Bhitai Dental and Medical College

Mirpurkhas

3. BDS, MSc

Assistant Professor

Department of Oral Pathology,

Bibi Aseefa Dental (SMBBMU)

College Larkana-Pakistan

4. MBBS, DCP, M.Phil (Hematology) Lecturer Pathology

Liaquat University of Medical and

Health Sciences Jamshoro, Sindh.

5. MBBS, M.Phil (Histopathology)

Assistant Professor Pathology

ISRA University Hyderabad, Sindh.

6. BDS, MPH

Assistant Professor and Head

Preventive and Community Dentistry Bhitai Dental and Medical College Mirpurkhas.

7. M.Phil (Research Scholar)

Centre for Human Genetics,

Hazara University Mansehra.

Correspondence Address:

Dr. Naeem Bukhari

Centre for Human Genetics,

Hazara University, Mansehra.

naeembukhari20@gmail.com

Article received on:

03/06/2020

Accepted for publication:

20/08/2020

\section{INTRODUCTION}

Cytopathological investigations enlightened significant content of aberrant squamous cells $(95 \%)$ while characterizing oral carcinomas in a distinct class of head and neck carcinomas. ${ }^{1-2}$ Since last decade, some novel approaches were made by scientists designing certain histopathological grading systems for squamous cellular carcinomas. Initially, cytopathological classification of malignant cells was made based upon morphological aspects of tumor cells. Later, tumor cells interaction within host cellular system was opted for histopathological grading. ${ }^{3-4}$ In current era of advancements in cellular micrometry assessing tumor cellular microenvironment, histopathological grading of tumor cells basis on patterns of cellular differentiation (well differentiated, poorly differentiated, moderately
Waqas Iqbal' ${ }^{1}$ Arhama Surwaich ${ }^{2}$, Surwaich Ali Channa ${ }^{3}$, Khalid Yousuf Memon ${ }^{4}$, Abdul Majid $^{5}$,

ABSTRACT... Objectives: To correlate CK-19 with different histopathological gradings of oral

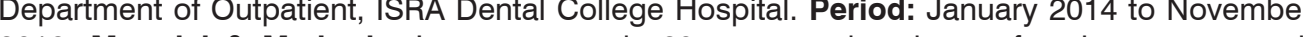
2019. Material \& Methods: In current study 60 suspected patients of oral squamous cell Institutional review board and patients' willingness to participate in the study was ensured. For statistical data analysis SPSS version 21.0 and Revman5.30 multiple tools were used. Results: Histopathological grading of sixty suspected cases of OSCCs was done into four different ( positive cases of OSCCs. CK-19 was found positive in 10 cases (83.3\%) in well differentiated Oral Squamous cell carcinomas, where only 2 cases $(16 \%)$ of moderately differentiated OSCCs with well differentiated and moderately differentiated Oral Squamous cell carcinomas. We highly recommend further research standardizing CK-19 as a promising histopathological grading Key words: $\quad$ CK-19, Histopathological Grading, Oral Squamous Cell Carcinomas.

Article Citation: Iqbal W, Surwaich A, Channa SA, Memon KY, Majid A, Iqbal Z, Bukhari. Association of CK-19 with histopathological grading of oral squamous cell carcinomas (OSCC). Professional Med J 2021; 28(2):247-252. https://doi.org/10.29309/TPMJ/2021.28.02.5067

differentiated and undifferentiated) nuclear metastasis and cellular keratinization..$^{5-6}$ Whereas, differential cytopathological dependent diagnosis adopted in routine histopathological laboratory settings ends up with delayed diagnosis. Which results in tumor progression from stage-III to stage-IV with the passage of time impacting patient survival at greater extent. ${ }^{7-9}$

From therapeutic aspect, detection of oral squamous cell carcinomas at earlier stage are more prone to effective treatment in comparison to adverse stage of tumors. Effective tumor prevention requires advance tumor detection methods at initial histopathological stage..$^{10-11}$

Practicing comprehensive tumor prognostic marker, cytokeratin-19 commonly referred as 
marker of cellular multiplication belonging from cytokeratin family of proteins has showed significant association with patterns of histopathological grading system. ${ }^{12}$

The main purpose of current study is to correlate CK-19 with routine histopathological grading system of oral squamous cell carcinomas (OSCCs) followed at ISRA Dental College, Isra University Hospital Hyderabad Sindh Pakistan.

\section{MATERIAL \& METHODS}

Current descriptive study based on multipurpose sampling method enrolled 60 suspected patients of oral squamous cell carcinomas for cancer diagnosis and histopathological evaluation at ISRA Dental College Hospital, Outpatient Department from January 2014 upto November 2019. Initially, $5 \mathrm{ml}$ of blood sample was collected from patients of both genders and isolated blood samples were further processed for RNA extraction by using mini RNA Extraction Qiagen kit method. ${ }^{13}$ Extracted RNA from patient samples was subjected to RT-PCR for detection of CK-19 mRNA expression. Cytokeratin-19 gene specific primers were taken according to Datta et al ${ }^{14}$;

CK19 (Forward CK1): -5'-AAG CTA ACC ATG CAG AAC CTC AAC GAC CGC - 3' CK19 (Reverse CK2): - 5' -TTA TTG GCA GGT CAG GAG AAG AGC C - 3'

Patients tested positive for cytokeratin-19 were furthered considered for surgical incisional biopsy collection and histopathological studies (Figure-1.1).

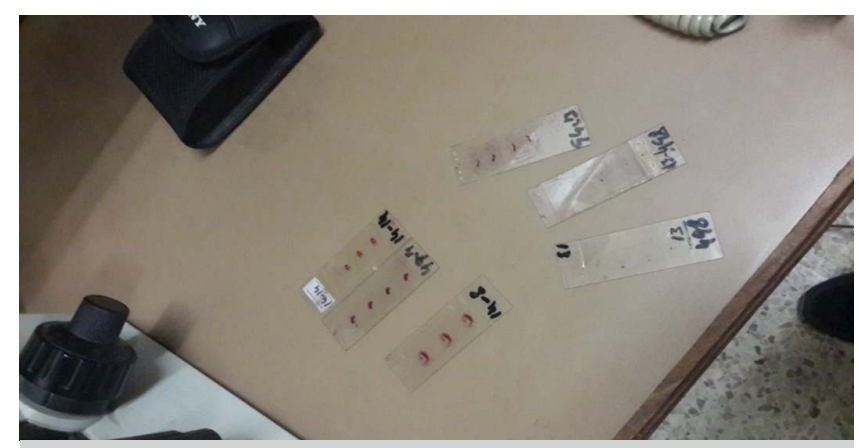

Figure-1.1. Histopathological slide preparation in histopathology laboratory. were excluded for further histopathological evaluations. Histopathological patterns of differentiation in oral squamous cellular carcinomas were further compared with cytokeratin-19 by using Polymerase chain reaction (PCR) kit method.

Oral squamous cell carcinoma cases were graded according to the degree of keratinization and pattern of cellular differentiation into four grades; Grade I: Tumor tissue showed well differentiated cells defined as $75-100 \%$ cells were differentiated. Grade II: Tumor tissue showed moderately differentiated cells defined as 50-75\% cells were differentiated. Grade III: Tumor tissue showed poorly differentiated tumors defined as $25-50 \%$ of cells were differentiated. Grade IV: Tumor tissue showed mostly undifferentiated cells called Anaplastic tumor, defined as $0-25 \%$ of cells were differentiated. ${ }^{15}$

Demographic details, gender, age, disease history and clinical conditions of histopathological confirmed with positive cytokeratin-19, Oral squamous cellular carcinomas cases were assessed upto four-year follow-up duration. Ethical approval was properly taken from Institutional review board and patients' willingness to participate in the study was ensured. For statistical data analysis SPSS version 21.0 and Revman 5.30 multiple tools were used.

\section{RESULTS}

Upon assessment of sixty suspected patients of mouth carcinomas, about twelve $(20 \%)$ principal cases were found positive for cytokeratin-19 tumor marker as well as histopathological confirmed cases of Oral squamous cell carcinomas OSCCs. Where rest of 48 cases (80\%) were found negative for cytokeratin-19 tumor marker and excluded for further analysis. Where CK-19 was found positive in 8 male patients and 04 female patients (Table-I).

Histopathological grading of OSCCs confirmed cases was done into four different gradings which include, poorly differentiated, moderately differentiated, well differentiated and undifferentiated OSCCs.

Where, patients tested negative for cytokeratin-19 


\begin{tabular}{|l|c|}
\hline CK-19 (PCR+ve) and & 12 \\
Histopathological confirmed OSCCs & 10 \\
Well differentiated OSCCs & 02 \\
Moderately differentiated OSCCs & 0 \\
Poorly differentiated OSCCs & 0 \\
Un-differentiated OSCCs & 07 \\
4 -year follow up survival & 05 \\
Deaths & 05 \\
Age-wise CK-19 Distribution: & 06 \\
Group A, 21-39.9 (y) & 01 \\
Group B, 40-59.9 (y) & 08 \\
Group C, $\geq 60$ & 04 \\
Gender: & 12 \\
Male & \\
Female & \\
Total = & \\
Table-I. Demographic characteristics and grading of \\
$\quad$ oral squamous cellular carcinomas.
\end{tabular}

Out of 12 (Cytokeratin-19) positive cases of OSCCs about 10 cases (83.3\%) were found histopathological well differentiated Oral Squamous cell carcinomas. where only 2 cases (16\%) of moderately differentiated OSCCs were positive against CK-19 (Table-I \& Figure-3.0).

Intriguingly, no one histological confirmed case with poorly- undifferentiated oral squamous cell and undifferentiated oral squamous cell carcinomas were detected in our principal study subjects. Highest CK-19 positivity trends (50\%) were found in above 40-year age patients in comparison to patients from 20-39-year age group (Table-I).

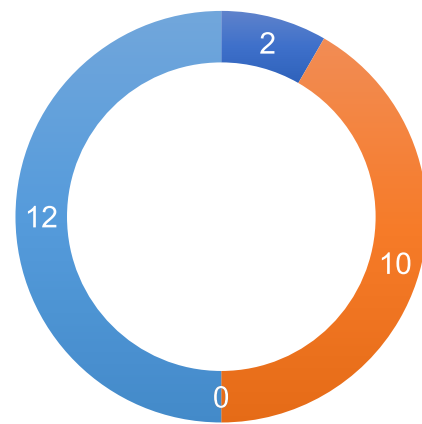

Moderaly differentiated OSCCs

well differentiated OSCCs

poorly differentiated OSCCs

un-differentiated OSCCs

Total

Figure-3.0. Pie chart showing Cytokeratin-19 in OSCCs cytological gradings.

Patient for four year follow up recurrence duration were monitored. Only seven patients were persistently positive for CK-19, where 5- patient were died during the monitoring phase of study.

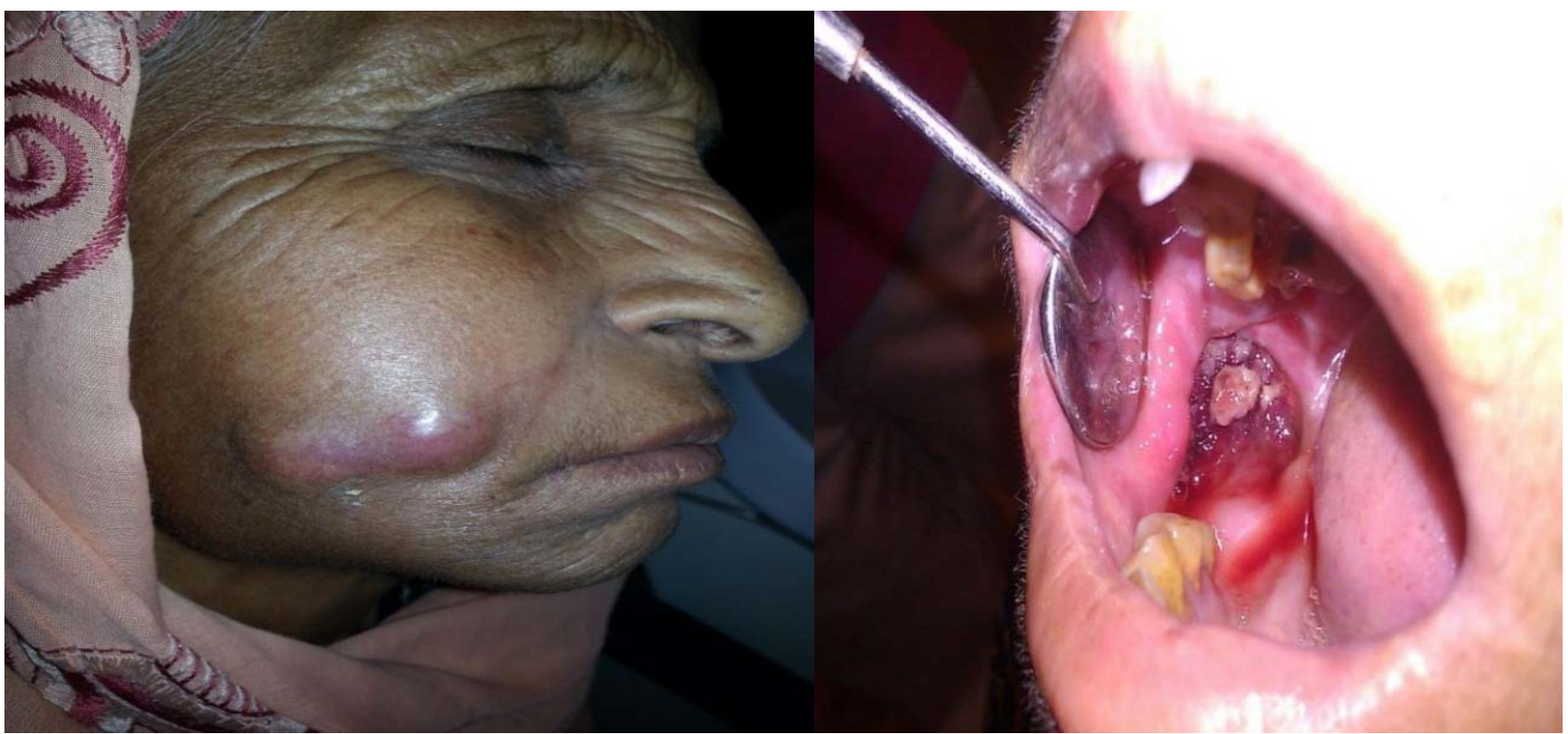

(a)

(b)

Figure-3.1a\&b. Photograph of a patient with oral squamous cell carcinoma as seen growing out of cheek with oral squamous cell carcinoma with open mouth and visible growth.

(Printed with permission of patient). 


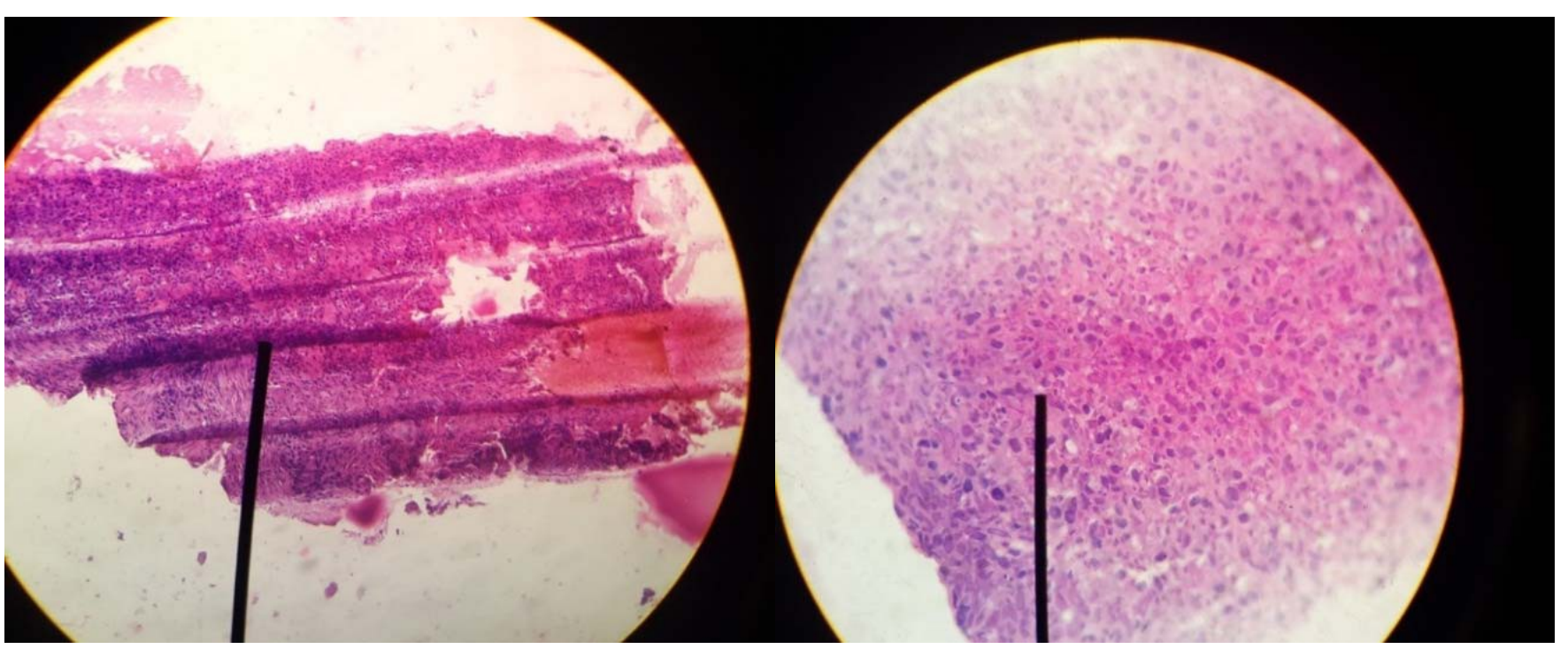

(a) H \& E staining $x 40$

(b) H \& E staining $\times 100$

Figure-3.2 a\& b. Microscopic features of a moderately differentiated squamous cell carcinoma.

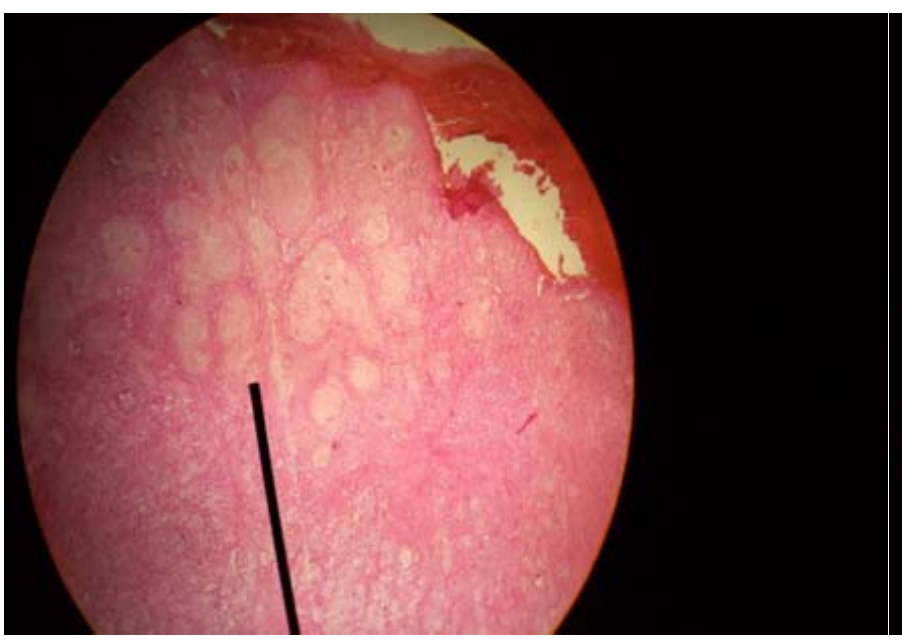

(a) H \& E staining $x 40$

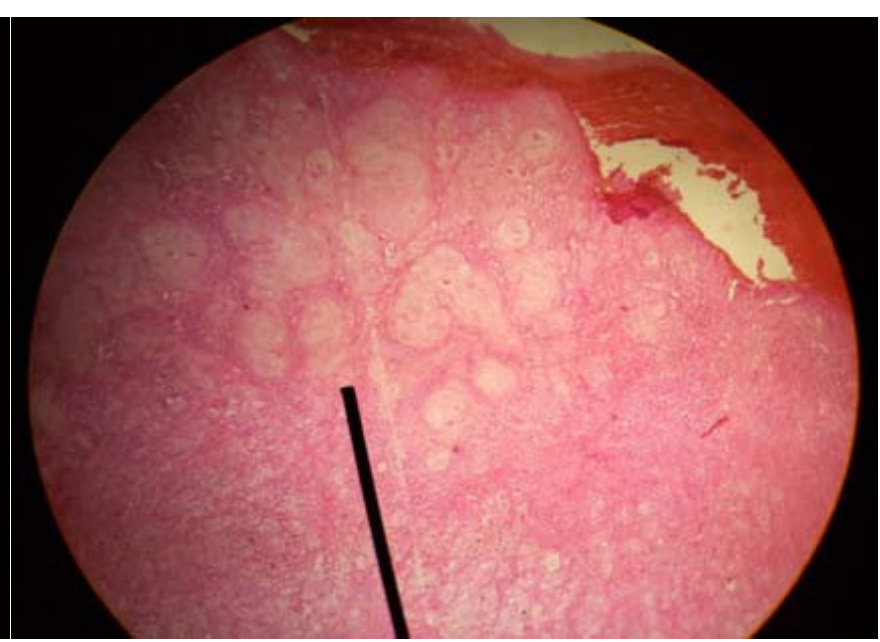

(b) H \& E staining $\times 100$

Figure-3.3 a\&b. Microscopic features of a well differentiated squamous cell carcinoma showing keratin pearls.

Oral squamous cellular carcinoma physiological and histopathological grading and correlation with CK-19 RT-PCR are also presented in Figure3.1A, 3.1B, 3.2, 3.3 as well.

To assess the exact association of CK-19 with histopathological grading, following specific conditions where chances of false positivity of CK-19 reverse transcriptase polymerase chain reactions can occur were pre-determined. Including, blood disorders in which CK-19 is induced in peripheral circulation under influence of cytokines. Illegitimate transcription, this occurs because of presence of small amounts of CK19 mRNA present in certain tissues in very low quantities due to contamination as well.

\section{DISCUSSION}

First time in Sindh, Pakistan our study correlated CK-19 with cytological differentiation of OSCCs and reported significant association (83\%) of CK-19 specifically with well differentiated oral squamous cellular carcinoma, $16.6 \%$ with moderately differentiated oral squamous cellular carcinomas. Where a previous study following collective efficacy of CK-19 oral squamous cellular 
carcinomas reported $56 \%$ efficacy based on 18 patient sample volume, $72 \%$ efficacy of CK-19 in well differentiated Oral squamous cellular carcinomas. ${ }^{16}$ Our outcomes are inconsistent with previously reported studies following differentiation patterns of oral squamous cellular carcinomas in Pakistan. Similarly, scientists reported significant association of CK-19 in histopathological grading of oral squamous cellular carcinomas. Furthermore, a significantly higher CK-19 score in moderately differentiated OSCCs than well-differentiated ones was reported. Previous studies examined the rate of CK-19 expression in relation to the grades of pathological differentiation in the OSCCs, detecting a positive association. ${ }^{16-17}$ Based upon existing literature, no one study predicted $100 \%$ efficacy of CK-19 grading oral squamous cellular carcinomas. The possible concerns include, limited number of study subjects, chances of cellular contamination, patient immune system parameters, genetic factors and potential of CK19 gene expression factors impacting cellular proliferation. Designing cellular proliferation pattern specific and CK-19 gene-based kits could help grading oral squamous cellular carcinomas at initial stage to mitigate existing OSCCs prognostic gap in under-developed areas. ${ }^{18}$

Some studies based on oral lichen planus (OLP) predicted impact of staining procedure over the expression of CK-19 gene, where other studies contradicted subjected concept and reported insignificant impact of staining procedures over the Ck-19 gene expression in Oral squamous cellular carcinomas. ${ }^{16,19}$ Our staining outcomes are also in accordance with previous reports and no effect of staining procedures was found impacting Ck-19 gene expression in Oral squamous cellular carcinomas.

\section{CONCLUSION}

Our outcomes suggest CK-19 has strong association with well differentiated and moderately differentiated Oral Squamous cell carcinomas. As there are few researches available in literature, therefore, more research data is necessarily required for further extension of this debate. We highly recommend further research specially in Pakistan standardizing CK-19 as a promising histopathological grading marker.

\section{Copyright $(20$ Aug, 2020.}

\section{REFERENCES}

1. Moore SR, Johnson NW, Pierce AM, Wilson DF. The epidemiology of mouth cancer: A review of global incidence. Oral Dis. 2000; 6:65-74.

2. John G Batsakis. The histology of oral cancer. In: Shah JP, Johnson NW, Batsakis JG, editors. Oral cancer. London: Martin Duntiz; 2003. pp. 129-64.

3. Broders AC. Squamous cell epithelioma of the lip. $J$ Am Med Assoc. 1920; 74: 9.

4. Jakobsson PA, Eneroth CM, Killander D, Moberger G, Martensson B. Histologic classification and grading of malignancy in carcinoma of the larynx. Acta Radiol. 1973; 12 (1): $1 \square 8$.

5. Lyon. Pathology and genetics of head and neck tumors. (IARC WHO Classification of Tumours). 2005; IARC Press.

6. Anneroth G, Batsakis J, Luna M. Review of the literature and a recommended system of malignancy grading in oral squamous cell carcinomas. Scand J Dent Res. 1987; 95 (3): 229-249.

7. Wangsa D, Ryott M, Avall-Lundqvist E, et al: Ki-67 expression predicts locoregional recurrence in stage I oral tongue carcinoma. $\mathrm{Br} J$ Cancer. 2008; 99:1121-1128.

8. Jung DW, Che ZM, Kim J, Kim K, Kim KY and Williams $D$ : Tumor-stromal crosstalk in invasion of oral squamous cell carcinoma: A pivotal role of CCL7. Int J Cancer. 2010; 127:332-344.

9. Centelles PV, Seoane-Romero JM, Gómez I, Diz-Dios P, de Melo NS and Seoane J: Timing of oral cancer diagnosis: Implications for prognosis and survival. Oral Cancer. Ogbureke KUE: InTech. 2012; pp. 173188

10. Dissanayaka WL, Pitiyage G, Kumarasiri PV, Liyanage $\mathrm{RL}$, Dias $\mathrm{KD}$ and Tilakaratne WM: Clinical and histopathologic parameters in survival of oral squamous cell carcinoma. Oral Surg Oral Med Oral Pathol Oral Radiol. 2012; 113:518-525.

11. Mehrpouya, M., Pourhashem, Z., Yardehnavi, N., \& Oladnabi, M. Evaluation of cytokeratin 19 as a prognostic tumoral and metastatic marker with focus on improved detection methods. Journal of Cellular Physiology. 2019; doi:10.1002/jcp.28768. 
12. Mackay I. Real-time PCR in microbiology: From diagnosis to characterization. Norfolk, England: Caister Academic Press. 2007:440.

13. Datta $Y$, Adams PT, Drobyski WR et al. Sensitive detection of occult breast cancer by the reversetranscriptase polymerase chain reaction. $J$ Clin Oncol 1994; 12: 475-482.

14. Neena D, Siddharth S, Keyuri P, Munira J. Histological grading of oral cancer: A comparison of different systems and their relation to lymph node metastasis. Natl J Comm Med. 2011; 2 (1):136-9.

15. Bombeccari, G. P., Giannì, A. B., \& Spadari, F. Immunoexpression of cytokeratin-19 in the oral lichen planus and related oral squamous cell carcinoma. Annali di stomatologia. 2018; 8(3), 104109. https://doi.org/10.11138/ads/2017.8.3.104.
16. Safadi RA, Musleh AS, Al-Khateeb TH, Hamasha AA. Analysis of immunohistochemical expression of k19 in oral epithelial dysplasia and oral squamous cell carcinoma using color deconvolution-image analysis method. Head Neck Pathol. 2010; 4(4):282 289.

17. Toyoshima T, Vairaktaris E, Nkenke E, et al. Cytokeratin 17 mRNA expression has potential for diagnostic marker of oral squamous cell carcinoma. J Cancer Res Clin Oncol. 134(4):515- 521. Erratum in: J Cancer Res Clin Oncol 2008; 34(4):523.

18. Alamgir, M. M., Jamal, Q., \& Mirza, T. Conventional clinical and prognostic variables in 150 oral squamous cell carcinoma cases from the indigenous population of Karachi. Pakistan journal of medical sciences. 2018; 32(3), 672-676.

19. Jacques CM, Pereira AL, Maia V, Cuzzi T, Ramos-e-Silva M. Expression of cytokeratins 10, 13, 14 and 19 in oral lichen planus. J Oral Sci. 2009 Sep;51(3):355-365.

\begin{tabular}{|c|c|c|c|}
\hline \multicolumn{4}{|c|}{ AUTHORSHIP AND CONTRIBUTION DECLARATION } \\
\hline Sr. \# & Author(s) Full Name & Contribution to the paper & Author(s) Signature \\
\hline 1 & Waqas lqbal & $\begin{array}{l}\text { Principal investigator, Patient } \\
\text { selection. }\end{array}$ & 175 \\
\hline 2 & Arhama Surwaich & $\begin{array}{l}\text { Patient acquisition, Clinical } \\
\text { diagnosis. }\end{array}$ & \\
\hline 3 & Surwaich Ali Channa & $\begin{array}{l}\text { Lab experiments, Quality } \\
\text { assessment. }\end{array}$ & \\
\hline 4 & Khalid Yousuf Memon & $\begin{array}{l}\text { Data compilation literature } \\
\text { search. }\end{array}$ & \\
\hline 5 & Abdul Majid & $\begin{array}{l}\text { Histopathological analysis \& } \\
\text { evaluations. }\end{array}$ & \\
\hline 6 & Zafar lqbal & $\begin{array}{l}\text { Patient monitoring, } \\
\text { Methodology, chapter. }\end{array}$ & \\
\hline 7 & Naeem Bukhari & $\begin{array}{l}\text { Manuscript drafting, study } \\
\text { design, Results. }\end{array}$ & \\
\hline
\end{tabular}

